\section{George Stiny}

Department of Architecture, 10-419 Massachusetts Institute of Technology 77 Massachusetts Avenue Cambridge, MA 02139 USA stiny@mit.edu

Keywords: shape grammar, design theory, rules, schemas, embedding, recursion, hierarchy

\section{Research}

\section{What Rule(s) Should I Use?}

Presented at Nexus 2010: Relationships Between Architecture and Mathematics, Porto, 13-15 June 2010.

Abstract. Rules in schemas apply to shapes in terms of embedding. This melds calculating with art and design, and has many uses in teaching and in practice.

\title{
Introduction
}

Every time I talk about shape grammars, and art and design, I'm asked exactly the same question - usually more than once:

Q1 What rule(s) should I use?

And Q1 is easy to answer:

A1 Use any rule(s) you want, whenever you want to.

There are plenty of rules to choose from and, because rules depend on embedding, any rule you use will do the job, or let you go on to something new. Calculating with shapes is an open-ended process - like art and design. You're always free to try another rule.

This is the best answer I know. It extends calculating in Turing's way with symbols using recursion and identity - in other words, calculating in the canonical way with allor-none bits (0's and 1's) - to calculating in my way with shapes using recursion and embedding. Turing's kind of calculating is logical and combinatory - it's just counting. But it can get hung up and crash because there may be no symbols or way of combining them to go on. My kind of calculating is phenomenal and involves seeing. Then you can always go on because whatever you see - anything at all - is OK. There are no non sequiturs or blind alleys. This doesn't matter. My answer is rarely greeted enthusiastically. Maybe my interlocutors want to hear something else. There are many things to ask. Their real question may go more like this:

Q2 Can you tell me how to design an $\mathrm{x}$, or what to do next when I'm designing an $\mathrm{x}$ ?

The problem with Q2 is that it's usually too hard - at least for me. I probably don't know how to design an x. I may know something about shape grammars and calculating with shapes and rules, but this doesn't mean I know the rules to use for any $\mathrm{x}, \mathrm{y}$, or $\mathrm{z}$. What I suggest may not be anything you would do or anyone else would try. I may be wrong. The only promise is that calculating goes on whatever rules you try - right or wrong for $\mathrm{x}, \mathrm{y}$, or $\mathrm{z}$, rules always work. Perhaps what's wanted is a little magic, so that designing isn't necessary. This may be too much to ask. I'm not a sorcerer, even if shapes and rules may sometimes seem preternatural. But there's a practical question in between these two extremes that may repay discussion:

Q3 How can I cook up rules to match what's in art and design?

My answer to Q3 subsumes other things I've tried in the past, for example, my scheme for kindergarten grammars using spatial relations defined in a given vocabulary of 
shapes. This is still a valuable technique in teaching and practice, but now I want something more freewheeling. Instead of a vocabulary of shapes and spatial relations, I'll start with a small lattice of schemas and combine them to get other schemas as they're needed. The rules in these schemas incorporate key ideas in algebras of shapes, from various branches of mathematics. These include embedding and parts (Boolean algebra), transformations (geometry), and shape boundaries (topology). This lets me calculate with shapes, so that what I see makes a difference in what I do. This is reason enough for my schemas, but there's another reason, too, that may make them inevitable. The rules in my schemas are easy to find throughout art and design. Pragmatic evidence matters a lot when deciding what rules to try. Rules that work, work.

\section{Getting started}

Different algebras of shapes are enumerated in this familiar array:

$$
\begin{array}{cccc}
\mathrm{U}_{00} & \mathrm{U}_{01} & \mathrm{U}_{02} & \mathrm{U}_{03} \\
& \mathrm{U}_{11} & \mathrm{U}_{12} & \mathrm{U}_{13} \\
& & \mathrm{U}_{22} & \mathrm{U}_{23} \\
& & \mathrm{U}_{33}
\end{array}
$$

In any algebra $U_{i j}$, the index i gives the dimension of the basic elements that make up shapes:

\begin{tabular}{|l|l|}
\hline dimension $\mathrm{i}=$ & basic elements \\
\hline 0 & points \\
\hline 1 & lines \\
\hline 2 & planes \\
\hline 3 & solids \\
\hline
\end{tabular}

All basic elements, except for points, have boundaries that are shapes. The basic elements in these shapes have smaller dimension:

\begin{tabular}{|l|l|}
\hline basic elements & boundary shapes made up of \\
\hline solids & planes \\
\hline planes & lines \\
\hline lines & points \\
\hline points & none \\
\hline
\end{tabular}

The index $\mathrm{j}$ is greater than or equal to the index $\mathrm{i}$. The index $\mathrm{j}$ gives the dimension of the space in which basic elements are defined, and combined and moved around, or, equivalently, the dimension of the transformations that apply to shapes. Shapes may be added or subtracted, and changed by the transformations. Shapes are parts of shapes that can be divided anywhere, and shapes fuse without divisions - once shapes go together they disappear in the result. 
There's a lot more than this, but this is plenty for now. With seeing as a guide, you can't go wrong with shape grammars. You don't have to define everything formally when you can follow your eyes. In fact, formal definitions have to live up to seeing in every way to be of any value at all. Your eyes are always the test. So let's take a look at my third question and not worry too much about being perfectly rigorous:

\section{Q3 How can I cook up rules to match what's in art and design?}

What schemas are in my lattice and what rules do they define? I have three sorts of operators in mind that let me define simple rules to move within algebras of shapes and between algebras of shapes. I can use these rules to go from one shape to another shape of the same kind, and to link shapes of different kinds. My operators involve parts of shapes, transformations, and boundaries:

(1) $\operatorname{prt}(\mathrm{x})$ determines a part of a shape $\mathrm{x}$,

(2) $t(x)$ transforms $x$ into another shape, and

(3) $b(x)$ gives the boundary shape of $x$.

The rules I want are in the schemas in this lattice:

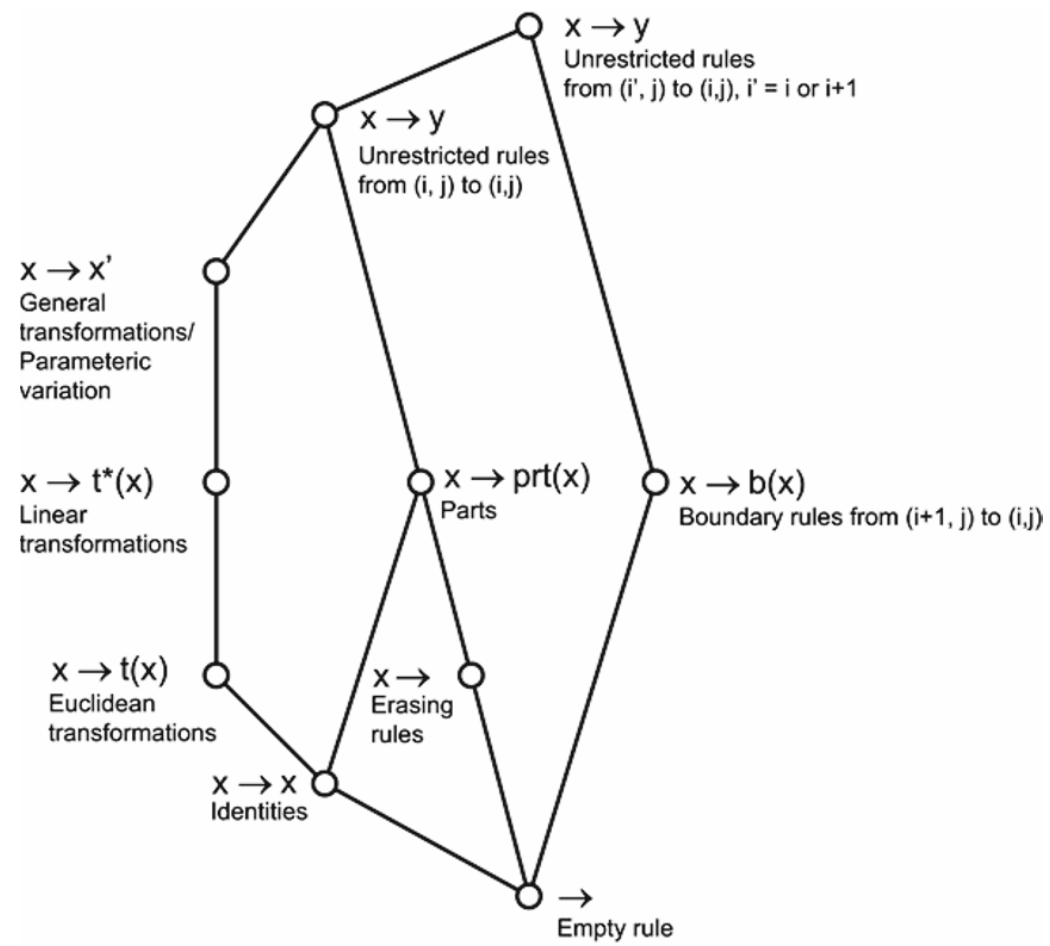

The lattice is defined in the customary way for subsets. Two schemas are connected if the rules in the lower one are also rules in the higher one. Rules for parts, transformations, and boundaries provide some of the rudiments to calculate with shapes in art and design.

Let's start at the bottom of my lattice and work up to the top, from restricted schemas to more general ones. I'll try to describe rules in terms of the least inclusive 
schemas in which they're defined. The idea is to show how little it takes to do a lot - in accord with Ockham's razor. The empty rule

is just the arrow that glues shapes together in spatial relations to define rules. The empty rule is as spare as you can get. It doesn't look like much because its left side and its right side are the empty shape. This captures the idea of an action - an unresolved impulse without saying what to see or what to do. The empty rule closes off my lattice, and in this sense, it's merely a technical device. But the empty rule may be useful in some additional ways, as well - for example, to define rules that apply in parallel to calculate in composite algebras that are the products of others. This allows for multiple shapes and sundry stuff to interact in various ways that may change as calculating goes on. The relations that make sense now may be nonsense later.

The schema

$$
\mathrm{x} \rightarrow \mathrm{x}
$$

and the schema

$$
\mathrm{x} \rightarrow
$$

are both directly above the empty rule. The one contains identities to fix the biggest parts of shapes, and the other, erasing rules for the smallest parts of shapes. Their top

$$
\mathrm{x} \rightarrow \operatorname{prt}(\mathrm{x})
$$

contains rules that pick out parts of shapes whatever their size - biggest, smallest, or in between. Together, rules of these three kinds show that shapes can be divided into parts in any way you like. Parts can be traced or cut out from here, there, or anywhere in any number of pieces. These rules are particularly useful when it comes to decomposing shapes into meaningful structures of various kinds, for example, into hierarchies or finite topologies (Boolean algebras and Heyting algebras). In shape grammars, these structures are defined on the fly as a result of what rules do, and they can alter erratically as rules are tried. Hierarchies and the like are retrospective, and aren't a prerequisite for calculating. It's just the reverse. The parts that are resolved in shapes are the outcome of calculating, and how these parts are related is determined by calculating, too. In shape grammars, no vocabulary of parts or structure of any kind is a prerequisite.

Identities in the schema $\mathrm{x} \rightarrow \mathrm{x}$ may be of special note. Many find them useless, because they apply to shapes to produce exactly the same ones. It seems that there's no reason to use identities to calculate. What good is calculating without effect - one shape $\mathrm{C}$ repeats monotonously with no relief:

$$
\mathrm{C} \Rightarrow \mathrm{C} \Rightarrow \ldots \Rightarrow \mathrm{C}
$$

But this kind of conspicuous redundancy isn't really vacuous. In many ways, identities are at the root of shape grammars and their use in art and design. Identities let me change things without lifting a finger, simply looking again to find new parts and define new relations. And this may be pretty dramatic, as, for example, in R. Mutt's (or is it Marcel Duchamp's?) infamous Fountain. Mr. Mutt opens our eyes with identities, and Duchamp and his friends - Beatrice Wood and Henri-Pierre Roché - say so in the 
ultimate issue of The Blind Man. (The blind man, indeed, not seeing in one way but seeing in another.)

The identities in the schema $\mathrm{x} \rightarrow \mathrm{x}$ also show how transformations work. An identity is a rule in the schema

$$
\mathrm{x} \rightarrow \mathrm{t}(\mathrm{x})
$$

if $\mathrm{t}$ is the identity transformation $(\mathrm{t}(\mathrm{x})=\mathrm{x})$, but $\mathrm{t}$ may be any other Euclidean transformation, as well. The transformation rules in the schema $\mathrm{x} \rightarrow \mathrm{t}(\mathrm{x})$ apply recursively to $\mathrm{t}(\mathrm{x})$, and in surprising ways when there's embedding. It's magic! For example, I can use transformation rules to rotate or reflect shapes by translating their parts. This isn't the kind of geometry I learned in school. Or I can turn pinwheels to rotate points that are fixed as rules are tried. That is to say, I can move points without any obvious way of moving them. It's a neat trick that's fun to do over and over again in various ways.

Of course, the Euclidean transformations aren't the end of it. They're included with affine transformations in the linear (projective) transformations in the schema

$$
\mathrm{x} \rightarrow \mathrm{t}^{*}(\mathrm{x})
$$

Linear transformations $t^{*}$ provide the foundation for perspective in drawing and painting. They're key in architectural practice and have many important uses elsewhere in design.

General transformations are given by $\mathrm{x}^{\prime}$ in the schema

$$
\mathrm{x} \rightarrow \mathrm{x}^{\prime}
$$

The transformation rules in the schema $\mathrm{x} \rightarrow \mathrm{x}^{\prime}$ allow for parametric variation of any sort - linear and not. They let me explore designs with shape schemas like Goethe's Urpflanze, too - but perhaps more generally, because organs (unit parts: atoms, bits, building blocks, cells, components, constituents, etc.) aren't predefined to permute and transform. The rules in my schemas use embedding to redefine parts again and again on the fly - in fact, every time a rule is tried. That's how rules match seeing. And that's why they work so well in art and design, and why they do far more than anyone expects.

The schema

$$
\mathrm{x} \rightarrow \mathrm{b}(\mathrm{x})
$$

is also above the empty rule $\rightarrow$. The boundary rules in this schema let me go from shapes with basic elements of dimension $i+1$ to shapes with basic elements of dimension i, so that I can use all kinds of shapes at the same time when I calculate. These rules mark the ends of lines, or outline shapes made up of planes, as an artist or designer might do this in a drawing.

Unrestricted rules finish off my lattice. They're in the twin schemas

$$
\mathrm{x} \rightarrow \mathrm{y}
$$

Like the empty rule $\rightarrow$ at the bottom, they're needed for technical reasons. But they have explanatory content, as well. The lower schema only contains rules with shapes $\mathrm{x}$ and $\mathrm{y}$ in a single algebra with basic elements of dimension $i$. The top schema also contains rules 
with shapes $\mathrm{x}$ and $\mathrm{y}$ in two algebras with basic elements of dimensions $\mathrm{i}+1$ and $\mathrm{i}$. This is why rules for parts and transformations, and rules for boundaries are different. A little later, I'll show how to define unrestricted rules using the schema for parts, $\mathrm{x} \rightarrow \operatorname{prt}(\mathrm{x})$.

\section{Going on}

The schemas in my lattice are just the beginning of the story, although I sometimes think that they're more than enough to keep me going for a long, long time. They illustrate the novel properties of shape grammars in some really easy and surprising ways. There's more art in them than anyone will ever see. The schema $\mathrm{x} \rightarrow \mathrm{x}$ for identities may be all I need to prove this. Mr. Mutt would probably agree. Nonetheless, there are additional kinds of schemas to define rules that are hard to avoid in art and design. They're very intuitive rules that seem almost inevitable in teaching and practice - rules for the kinds of things almost everyone tries to do.

One way to define additional schemas is to take the inverses of the schemas in my lattice. Flipping the sides of schemas forms their inverses. Thus for the schema (or rule) $\mathrm{x} \rightarrow \mathrm{y}$, the inverse is $\mathrm{y} \rightarrow \mathrm{x}$. Inverses for some of the schemas in my lattice are given in this table:

\begin{tabular}{|l|l|l|l|l|}
\hline schema & $\mathrm{x} \rightarrow$ & $\mathrm{x} \rightarrow \operatorname{prt}(\mathrm{x})$ & $\mathrm{x} \rightarrow \mathrm{t}(\mathrm{x})$ & $\mathrm{x} \rightarrow \mathrm{b}(\mathrm{x})$ \\
\hline inverse & $\rightarrow \mathrm{x}$ & $\operatorname{prt}(\mathrm{x}) \rightarrow \mathrm{x}$ & $\mathrm{t}(\mathrm{x}) \rightarrow \mathrm{x}$ & $\mathrm{b}(\mathrm{x}) \rightarrow \mathrm{x}$ \\
\hline alternate form & & $\mathrm{x} \rightarrow \operatorname{prt}^{-1}(\mathrm{x})$ & $\mathrm{x} \rightarrow \mathrm{t}^{-1}(\mathrm{x})$ & $\mathrm{x} \rightarrow \mathrm{b}^{-1}(\mathrm{x})$ \\
\hline
\end{tabular}

All of these inverses are pretty interesting, with precedents in art and design. Only the one for transformations, $\mathrm{t}(\mathrm{x}) \rightarrow \mathrm{x}$, may be superfluous, because the inverses of transformations are transformations themselves. Any rule in the inverse $t(x) \rightarrow x$ is already a rule in the schema $\mathrm{x} \rightarrow \mathrm{t}(\mathrm{x})$ in my lattice. This is explicit in the alternate form $\mathrm{x} \rightarrow \mathrm{t}^{-1}(\mathrm{x})$ - but more on the use of alternative forms one paragraph down.

The three schemas $\rightarrow \mathrm{x}, \operatorname{prt}(\mathrm{x}) \rightarrow \mathrm{x}$, and $\mathrm{b}(\mathrm{x}) \rightarrow \mathrm{x}$ are especially nice. The rules in the schema $\rightarrow \mathrm{x}$ let me act without seeing anything at all, whether something is there or not. I can splash a wall with colors and go on from what I see in the sundry blots and stains, in the way Leonardo da Vinci urges - "if you consider them [blots and stains] well, you will find really marvelous ideas." I may try a rule in $\rightarrow \mathrm{x}$ and identities in the schema $\mathrm{x} \rightarrow \mathrm{x}$ to get what I want, or I can use $\rightarrow \mathrm{x}$ more than once with $\mathrm{x} \rightarrow \mathrm{x}$ in a coordinated way. (This looks like action painting, where $\rightarrow \mathrm{x}$ may be a procedural description for shapes - splash like so to get an x.) Perhaps there are blots and stains that need to be completed to get the right result - a contour needs to be closed up or an area needs to be filled in. Then rules in the schema $\operatorname{prt}(\mathrm{x}) \rightarrow \mathrm{x}$ let me find parts and add what's missing or left out. Or maybe there's a contour that should be filled in with a boundary rule in the schema $\mathrm{b}(\mathrm{x}) \rightarrow \mathrm{x}$ - something like drawing in a coloring book to shade in an open area and erase its outline, as well.

The inverses in my table are useful schemas, but they're awkward for what I want to try next in a mathematical fashion. For this, I need another way of saying the same thing. These alternate forms are already in place. Instead of flipping schemas, I'll use an inverse notation for parts and boundaries that copies my notation for transformations. Instead of the schema 


$$
\operatorname{prt}(\mathrm{x}) \rightarrow \mathrm{x}
$$

that reads "part of $\mathrm{x}$ goes to $\mathrm{x}$," I'll use the alternate schema

$$
\mathrm{x} \rightarrow \operatorname{prt}^{-1}(\mathrm{x})
$$

where " $\mathrm{x}$ goes to a shape with $\mathrm{x}$ as a part." The variable $\mathrm{x}$ has twin values in these schemas - the rule $\mathrm{A} \rightarrow \mathrm{B}$ is in $\operatorname{prt}(\mathrm{x}) \rightarrow \mathrm{x}$ for $\mathrm{x}=\mathrm{B}$, and in $\mathrm{x} \rightarrow \operatorname{prt}^{-1}(\mathrm{x})$ for $\mathrm{x}=\mathrm{A}$. (The duality for parts is clear in algebra, topology, etc. Then $\operatorname{prt}(\mathrm{x})$ corresponds to an ideal, and $\operatorname{prt}^{-1}(\mathrm{x})$ to a filter.) Equally, the schema

$$
\mathrm{b}(\mathrm{x}) \rightarrow \mathrm{x}
$$

that reads "the boundary of $\mathrm{x}$ goes to $\mathrm{x}$," has the alternate schema

$$
\mathrm{x} \rightarrow \mathrm{b}^{-1}(\mathrm{x})
$$

in which "x goes to a shape with the boundary $\mathrm{x}$. " This is something like using passive verbs in place of active ones. It's usually safe to go from one voice to another with no serious change in meaning, even if there always seems to be a mellifluous choice - I guess pleasing sounds also sound right.

I can combine the schemas in my lattice and their inverses to define compound rules that are widely used in art and design. I'll try two methods of combination: composition and addition. This isn't the end of it but only a start that may need to be augmented or revised, as experience demands. I've just started to play with this stuff. There's more to explore to be fully confident of the results. But this is no reason not to see how far I can go with what I've got to get others to wander around in this region to see what kinds of schemas and rules they can find.

Suppose I outline a shape $\mathrm{x}$, as I look at prt(x). (There are many ways to think about this. Terry Knight tries "representational ambiguity" - my next rule includes a rule she defines.) Maybe I see a random patch

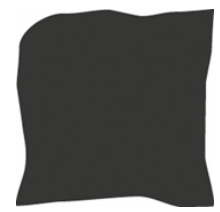

in the clouds or in smudges on a dirty window, and I draw the square

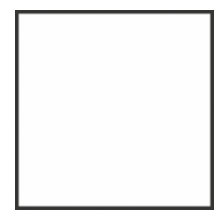

on a sheet of paper on my desk. Then I've used the rule

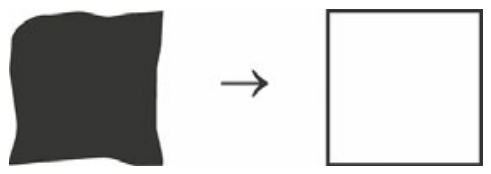


in the schema

$$
\operatorname{prt}(\mathrm{x}) \rightarrow \mathrm{b}(\mathrm{t}(\mathrm{x}))
$$

The transformation $\mathrm{t}$ takes

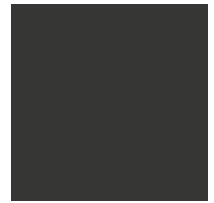

from its part in the clouds to my desk - no doubt, with a change in scale - where the boundary operator $\mathrm{b}$ gives me the outline I want

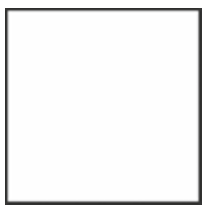

(More explanation may be superfluous, but detail is welcome. My rule in the schema $\operatorname{prt}(\mathrm{x}) \rightarrow \mathrm{b}(\mathrm{t}(\mathrm{x}))$ erases the original image - the wind blows it away, or it rains, which works for clouds and smudges alike. To leave the image alone, I need a rule in the schema $\operatorname{prt}(\mathrm{x}) \rightarrow \operatorname{prt}(\mathrm{x})+\mathrm{b}(\mathrm{t}(\mathrm{x}))$. This new schema is defined with addition. Then there are rules in the schema $\mathrm{x} \rightarrow$ to erase clouds or smudges to keep only my drawing. But the schema $\operatorname{prt}(\mathrm{x}) \rightarrow \mathrm{b}(\mathrm{t}(\mathrm{x}))$ is the crux of what I want to show now. Note, too, that color, shading, texture, etc. in clouds and smudges are something to calculate with, in schemas and rules. This takes weights. Their use is an open area of untapped promise.)

The schema $\operatorname{prt}(\mathrm{x}) \rightarrow \mathrm{b}(\mathrm{t}(\mathrm{x}))$ is neither in my lattice nor the inverse of a schema that is, but it's easy to define by composition using such schemas:

$$
\begin{aligned}
& \mathrm{x} \Rightarrow \operatorname{prt}^{-1}(\mathrm{x}) \Rightarrow \mathrm{t}\left(\operatorname{prt}^{-1}(\mathrm{x})\right) \Rightarrow \mathrm{b}\left(\mathrm{t}\left(\operatorname{prt}^{-1}(\mathrm{x})\right)\right)
\end{aligned}
$$

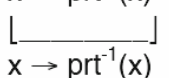

$$
\begin{aligned}
& \mathrm{x}=\mathrm{x} \\
& \mathrm{L}_{\mathrm{x} \rightarrow \mathrm{t}(\mathrm{x})} \\
& x=\operatorname{prt}^{-1}(x) \\
& \left\lfloor_{x \rightarrow b(x)}\right.
\end{aligned}
$$

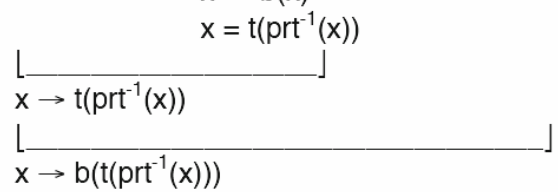

The idea is to extend a series of expressions starting with $\mathrm{x}$, to get a new schema. The schemas I already have are applied in this process, so that their left sides correspond to expressions of increasing size. A schema is defined if I put an arrow between $\mathrm{x}$ and any expression in the series. (Calculating with schemas isn't the only way to get new ones. I can combine expressions that I've built up by composing my operators and their inverses. 
This gives the schema $\operatorname{prt}(\mathrm{x}) \rightarrow \mathrm{b}(\mathrm{t}(\mathrm{x}))$. But it may pay to calculate first, to describe schemas in a uniform way that helps to classify them, and to see and say what they do.)

The schema

$$
\operatorname{prt}(\mathrm{x}) \rightarrow \mathrm{b}(\mathrm{t}(\mathrm{x}))
$$

in the form

$$
\mathrm{x} \rightarrow \mathrm{b}\left(\mathrm{t}\left(\operatorname{prt}^{-1}(\mathrm{x})\right)\right)
$$

is a kind of speedup schema that allows for multiple actions at once. The rule

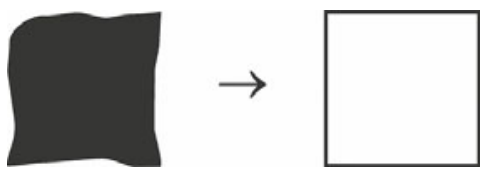

in this schema may look simple, but there's a lot to it - at least in terms of the schemas in my lattice. But this may seem odd. It may be more intuitive to define the rule directly instead of defining three other rules to get this easy result. Should parsimony and formal scruples limit the schemas I use? No, I don't think so. I'm not keen on any kind of morality when it comes to calculating, or to art and design. Schemas should define rules according to what artists and designers see and do, without a lot of work. I'm a big fan of exuberant (prodigal) redundancy, especially when there are easy results. But redundancy may make it hard to see what's going on and to talk about how various schemas and rules fit together. Defining some things from others may repay the effort. It organizes schemas and rules, and it helps to remember ones that have been useful in the past and to suggest new things to try. Thinking up schemas from scratch may be the hard way to get what you want, when you can change schemas and combine them to take advantage of what you know - experience counts. I'm a big fan of composition, as well.

A lot of redundancy is built into composition from the start. Suppose I work backwards from the square

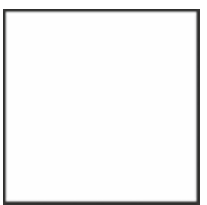

on the piece of paper on my desk to the shape

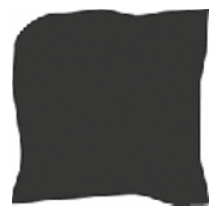

in the clouds. Then I get the schema

$$
\mathrm{x} \rightarrow \operatorname{prt}\left(\mathrm{t}\left(\mathrm{b}^{-1}(\mathrm{x})\right)\right)
$$

and its inverse

$$
\operatorname{prt}\left(\mathrm{t}\left(\mathrm{b}^{-1}(\mathrm{x})\right)\right) \rightarrow \mathrm{x}
$$

defines the rule 


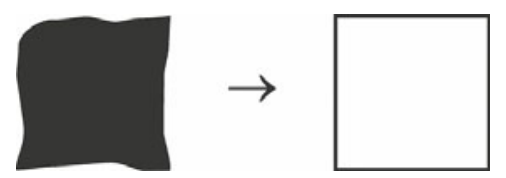

Composition is pretty flexible - there may be many ways to do the same thing with a different twist. Maybe you can find another schema to define my rule. But being clever isn't the goal, seeing is. Embedding is still the key. Without embedding, schemas - no matter how clever - don't go very far.

All sorts of schemas are defined using composition. The schema

$$
\mathrm{x} \rightarrow \mathrm{b}(\mathrm{b}(\mathrm{b}(\mathrm{x})))
$$

lets me go from a solid to its vertices, and the schema

$$
\mathrm{x} \rightarrow \mathrm{b}(\mathrm{b}(\mathrm{x}))
$$

from a solid to its edges, or from a plane to its vertices. And inverses run through Kandinsky's point and line to plane in many ways. The schema

$$
\mathrm{x} \rightarrow \mathrm{b}^{-1}\left(\operatorname{prt}^{-1}(\mathrm{x})\right)
$$

turns points into lines, lines into planes, etc. - say, a square plane into a solid cube. But compositions may not be novel. The schema $x \rightarrow \operatorname{prt}(\mathrm{x})$ includes the composite schema $\mathrm{x} \rightarrow \operatorname{prt}(\operatorname{prt}(\mathrm{x}))$. A part of a part of a shape $\mathrm{x}$ is a part of $\mathrm{x}$. In the same way, the schema $\mathrm{x} \rightarrow \mathrm{t}(\mathrm{t}(\mathrm{x}))$ is a frill - transformations are closed under composition.

The schema $\mathrm{x} \rightarrow \operatorname{prt}(\mathrm{x})$ and its inverse have a neat composition

$$
\mathrm{x} \rightarrow \operatorname{prt}^{-1}(\operatorname{prt}(\mathrm{x}))
$$

in a universal schema for all rules - let prt(x) be the empty shape that's a part of every shape. This shows how to get everything from nothing, but it says precious little about specific rules. The schemas in my lattice, and inverses, composition, and addition aren't just math. The aim is to hone schemas to describe and classify rules in useful (heuristic) detail - at least for the time being - for teaching and practice in art and design. Rules are all the same in my universal schema - there's scant to tell them apart in terms of the shapes they contain, or to describe the relations they may define.

Composition is hugely productive. Nonetheless, schemas combine in other ways, as well. I can use the plus sign (+) to link them in additions, so that the resulting schemas are explicitly recursive. For example, I may want to design a symmetrical pattern. Then rules in the schema

$$
\mathrm{x} \rightarrow \mathrm{x}+\mathrm{t}(\mathrm{x})
$$

work perfectly, when the transformations $t$ are the generators of a symmetry group. The identity $\mathrm{x} \rightarrow \mathrm{x}$ and the schema $\mathrm{x} \rightarrow \mathrm{t}(\mathrm{x})$ do the trick in the sum

$$
\begin{aligned}
& x \rightarrow x \\
+ & x \rightarrow t(x) \\
\hline x & \rightarrow x+t(x)
\end{aligned}
$$


The rules in this addition schema are in the inverse $\mathrm{x} \rightarrow \operatorname{prt}^{-1}(\mathrm{x})$, and they apply recursively to $\mathrm{x}$ and $\mathrm{t}(\mathrm{x})$. I used them nearly 35 years ago in "Two Exercises in Formal Composition." But my exercises weren't compositional in the logical sense in which parts are independent in combination - this takes labels or like devices to skirt ambiguity. The idea was to give rules for synthesis/analysis, so that this is a continuous process in design. Addition rules are further described in my scheme for kindergarten grammars, with a host of examples from Froebel's building gifts and tablets, H. G. Wells's imperial Floor Games, and basic design curricula of various kinds. And inverses of addition rules subtraction rules - are defined and tried in many ways, too. Knight calls the rules in the schema $\mathrm{x} \rightarrow \mathrm{x}+\mathrm{t}(\mathrm{x})$ "basic rules" and enumerates their properties when embedding is limited to identity. She uses basic rules - alone and also in "color grammars" - in her studio on computational design at MIT.

(Deciding what to say about schemas is never obvious - schemas can be described in different ways for different purposes that may or may not be meaningfully related. For example, both $\mathrm{x} \rightarrow \mathrm{t}(\mathrm{x})$ and $\mathrm{x} \rightarrow \mathrm{x}+\mathrm{t}(\mathrm{x})$ are special versions of the addition schema $\mathrm{x} \rightarrow \operatorname{prt}(\mathrm{x})+\mathrm{t}(\mathrm{x})$, when $\operatorname{prt}(\mathrm{x})$ is the empty shape or $\mathrm{x}$. This presents new possibilities to explore, some of everyday use in design. Suppose I want to move the left-most square in the shape

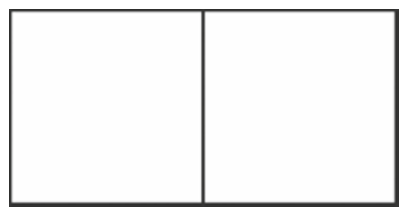

and leave the right square intact. But what happens if I try to translate the rectangle in the shape and keep the two squares, or if I alter one square and keep the other one and the rectangle? How many squares and rectangles are there? Are you sure? Do weights make a difference? How about composite algebras? It's no use trying to cover everything all at once. In what follows, I consider $\mathrm{x} \rightarrow \mathrm{t}(\mathrm{x})$ and $\mathrm{x} \rightarrow \mathrm{x}+\mathrm{t}(\mathrm{x})$ in terms of transformations only. This is far from the end of it - there are parts and other things to account for, too.)

There are new rules in the more general schema

$$
\mathrm{x} \rightarrow \mathrm{x}+\mathrm{x}^{\prime}
$$

to handle movement, and parametric or alternative views in sums. This is clear in art and design - for example, in traditional Chinese window grilles with their "checkerboard" lattice designs (Euclidean transformations may do in this case), cubist paintings, and Aalto, Scharoun, Klee, and Duchamp (Nude Descending a Staircase (No.2)). And then the fully general schema

$$
\mathrm{x} \rightarrow \mathrm{x}^{\prime}+\mathrm{x}^{\prime \prime}
$$

is good for Chinese ice-ray lattices. The rules for ice-rays divide polygons into polygons triangles, quadrilaterals, pentagons, etc. into different pairs of these figures. A polygon $\mathrm{x}$ goes to a sum of its transformations $\mathrm{x}^{\prime}$ and $\mathrm{x}^{\prime \prime}$ in a fractal-like fashion 


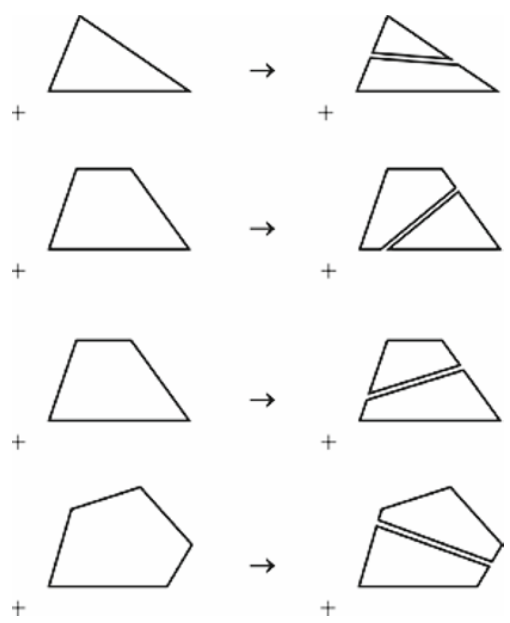

This may be better expressed with division rules in the schema

$$
\mathrm{x} \rightarrow \operatorname{div}(\mathrm{x})
$$

The schemas $\mathrm{x} \rightarrow \mathrm{x}^{\prime}+\mathrm{x}^{\prime \prime}$ and $\mathrm{x} \rightarrow \operatorname{div}(\mathrm{x})$ produce the same result when the operator $\operatorname{div}(\mathrm{x})$ divides $\mathrm{x}$ into $\mathrm{x}^{\prime}$ and $\mathrm{x}^{\prime \prime}$. Addition and division look alike, although some - notably Christopher Alexander - try to make a big deal out of this "timeless" distinction. (Timelessness is no guarantee that a distinction isn't vacuous. In fact, it seems that many time-honored distinctions fail when examined in terms of shapes and rules. This is another way of showing how embedding works and what it does, and why seeing instead of counting is a good way to calculate.) Also notice that $\mathrm{x} \rightarrow \operatorname{div}(\mathrm{x})$ shows how to construct ice-ray windows. It's easy to imagine an artisan following the rules it defines to divide polygons with sticks, adding them in this way or that between the sides of polygons to keep everything rigid, from the empty window frame to the penultimate open areas. No one doubts that calculating with rules is rational. For ice-rays, it seems, this is rational design, too. Maybe I should include $\mathrm{x} \rightarrow \operatorname{div}(\mathrm{x})$ in my lattice. It's obviously useful, and it has widespread intuitive appeal. It's no trouble to add in. I guess I'd put it above the schema $\mathrm{x} \rightarrow \mathrm{x}$, so that identities are division rules, and in between one of the three schemas for transformation rules and the schema for parts, $\mathrm{x} \rightarrow \operatorname{prt}(\mathrm{x})$. The only downside is an increase in redundancy with respect to addition and the schema $\mathrm{x} \rightarrow \mathrm{x}^{\prime}+\mathrm{x}^{\prime \prime}$, and perhaps, too, the loss of some elegance in a sloppier lattice that includes more than algebras of shapes require.

The division schema $\mathrm{x} \rightarrow \operatorname{div}(\mathrm{x})$ always surprises me: its results are everywhere I look. Rules in the schema are used in art and architecture. In addition to ice-rays, there are examples of the schema in the modernist paintings of Georges Vantongerloo and Fritz Glarner - perpendicular divisions or nearly perpendicular ones - in the Malagueira housing project of Alvaro Siza - perpendicular divisions again - and in Medieval building plans in Venice - neat tripartite divisions with T-cuts or parallel ones. Even Frank Gehry uses the schema in his fancy roofs - so much for originality! But really, all of these examples are distinct. There's no mistaking one for another.

I can always expand a schema by adding copies of it, where $\mathrm{t}(\mathrm{x}) \rightarrow \mathrm{t}(\mathrm{y})$ is a copy of the schema $\mathrm{x} \rightarrow \mathrm{y}$ under a transformation $\mathrm{t}$. (A schema and its copies are equal, because 
rules apply under transformations.) This lets me find similar parts of a shape in parallel and change them in similar ways. For example, if I use a reflection, I can define schemas for bilateral symmetry in classical building plans. Of special note, Palladian villa plans start off with rules to proportion grid cells - they're in this schema

$$
\begin{aligned}
& \mathrm{x} \rightarrow \mathrm{x}+\mathrm{x}^{\prime} \\
& +\mathrm{t}(\mathrm{x}) \rightarrow \mathrm{t}\left(\mathrm{x}+\mathrm{x}^{\prime}\right) \\
& \hline \mathrm{x}+\mathrm{t}(\mathrm{x}) \rightarrow\left(\mathrm{x}+\mathrm{x}^{\prime}\right)+\mathrm{t}\left(\mathrm{x}+\mathrm{x}^{\prime}\right)
\end{aligned}
$$

and in comparable ones. Then rules in the inverses of schemas like this

$$
\begin{gathered}
x \rightarrow x^{\prime}+x^{\prime \prime} \\
+\mathrm{t}(\mathrm{x}) \rightarrow \mathrm{t}\left(\mathrm{x}^{\prime}+\mathrm{x}^{\prime \prime}\right) \\
\mathrm{x}+\mathrm{t}(\mathrm{x}) \rightarrow\left(\mathrm{x}^{\prime}+\mathrm{x}^{\prime \prime}\right)+\mathrm{t}\left(\mathrm{x}^{\prime}+\mathrm{x}^{\prime \prime}\right)
\end{gathered}
$$

or alternatively,

$$
\mathrm{x}+\mathrm{t}(\mathrm{x}) \rightarrow \operatorname{div}(\mathrm{x})+\mathrm{t}(\operatorname{div}(\mathrm{x}))
$$

concatenate grid cells in room layouts. Once again, there are shared means and distinct ends - the schema $\mathrm{x} \rightarrow \mathrm{x}+\mathrm{x}^{\prime}$ is in Aalto, Scharoun, Klee, and Duchamp, and the schemas $\mathrm{x} \rightarrow \mathrm{x}^{\prime}+\mathrm{x}^{\prime \prime}$ and $\mathrm{x} \rightarrow \operatorname{div}(\mathrm{x})$ are good for ice-ray lattices, etc. Is there no end of these surprising correspondences? It's neat to see just how far schemas go. And this exercise isn't gratuitous - it builds a repertoire of schemas with workable outcomes that inform seeing and making in education and practice. In fact, this may be an answer to the elusive goal of effective studio teaching in art and design, and a useful basis for openended, creative practice, too.

My ability to define new schemas implies new lattices that tie things together in memorable ways. Using some of what I've done up to now with addition gives me the following lattice for transformation rules:

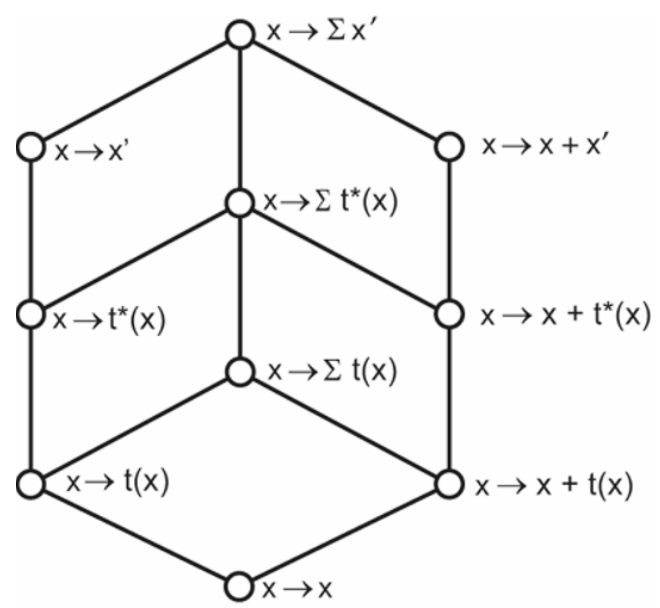

The only new wrinkle is summation. Rules in each of the three summation schemas are good for fractals, fractal-like patterns, and much more - rules for ice-rays are in $\mathrm{x} \rightarrow \Sigma \mathrm{x}^{\prime}$. The location of the summation schemas in the lattice shows how rules for fractals include rules for symmetry patterns. (It's fun to notice, too, that any rule $\mathrm{x} \rightarrow \mathrm{y}$, with shapes $\mathrm{x}$ 
and $\mathrm{y}$ in a given algebra, has the form $\mathrm{x} \rightarrow \Sigma \mathrm{t}(\operatorname{prt}(\mathrm{x}))$, or its inverse. There are two cases: $\operatorname{prt}(\mathrm{x})$ is the empty shape or a basic element. This gives details that the universal schema $\mathrm{x} \rightarrow \operatorname{prt}^{-1}(\operatorname{prt}(\mathrm{x}))$ doesn't - at least it involves the first table at the beginning of this essay. How would you use the boundary operator $\mathrm{b}$ to define rules with shapes $\mathrm{x}$ and $\mathrm{y}$ in different algebras to involve the second table?)

A question I'm asked almost as frequently as

Q1 What rule(s) should I use?

is this one:

Q4 What should I do in the studio?

There are many curricular options in my schemas, and in the way they're defined. Most of these are untried and so, full of undimmed promise. This is what I'd do first, although other scenarios are equally plausible, including ones that simply augment the projectoriented studios that are the norm today. To start, I'd teach about embedding and rules, with no math or fancy technology. Drawing with tracing paper is all it takes - trace this and redraw the rest. Repeat this over and over again until you're satisfied, noting each time what you see, A, and what you add, B. That's the rule you've used: A $\rightarrow$ B. (The part A includes what's left out, but A may be more if it overlaps B.) Don't be afraid to change your mind freely about what you see. Pretend you're looking for the first time you've found something new - and trace and redraw what you like, without thinking too much about what this should be. Then I'd go through examples of various schemas how they're defined and how they classify rules, including the special ones you've tried. Schemas are good mnemonics. They're easy to remember because they lack the spatial detail in individual rules or sequences of rules. Schemas can be given in plain words and recalled by name. They let you talk about what you see and do in your own terms, and how this might go on. Schemas can be changed and combined, so that you can cook up the ones you need as you need them. And you're free to try the rules they define on whatever you see. Schemas define rules for different purposes at different scales, with novel results. The division schema $\mathrm{x} \rightarrow \operatorname{div}(\mathrm{x})$ is good for vernacular designs in the crafts and for art and architecture, and surely, for city design, as well. (Savannah, Georgia repeats a motif in Chinese window grilles.) Art and design are observational - what you find here may work there when you notice that things look the same or change them to match. The reason for schemas isn't to decide or limit what you can do but to define rules for seeing, so that you're free to go on as you please. Whether I tell you or not, the goal is to learn to calculate with shapes and rules - to use your eyes to see and do more. (A similar task is to get computers to define and use schemas and rules with embedding anything less is visually incomplete. This may herald full-fledged computer support for art and design.)

Of course, there's also the desire - perhaps it's an obligation - to teach students to be creative. I'm asked about creativity whenever I talk about schemas and studios. This gives me the chance to test the answers I've heard. None of them really works, except one that enjoys broad yet mute approval. It seems that everybody knows how to get something new, but is afraid to let on. In a word, the secret formula is this:

copy 
This has to be wrong. At MIT, entering graduate students are given a manual warning them about copying and its perils, albeit this may spoil their chances for success in science, engineering, management, and architecture. (Only the humanities may be immune. Scholars aren't scribes, but how about writers and poets: "poets steal ... and good poets make it into something better, or at least something different.") Science depends on repeatable experiments and results. And it's hard trying to imagine any kind of design without some kind of copying - "reverse engineering" and "best practice" are exactly that, best practice. Noticing someone else's rules and checking them out is flagrant copying, and it's learning to use schemas, as well - maybe the very schemas creative artists and designers already share. Is this kind of learning bad? In fact, using a rule $\mathrm{A} \rightarrow \mathrm{B}$ to calculate with shapes is copying: trace everything except $\mathrm{A}$ and copy $\mathrm{B}$. No copying means no calculating - so much for MIT! The loss is pretty small, given what's at stake. We're admonished again and again not to copy in school and in professional life - it's cheating. That's the final word. But what are you doing if you copy

\section{cheating}

letter for letter to see how terrible this is - and $\mathrm{h}$ happens to look like $\mathrm{r}$ ? (The typographical rule

$$
{ }_{+} \mathrm{h} \rightarrow{ }_{+} \mathrm{r}
$$

is in the schema $x \rightarrow \operatorname{prt}(\mathrm{x})$ in my original lattice - or in a more expansive schema, say, $\mathrm{x} \rightarrow \operatorname{prt}(\mathrm{x})^{\prime}$, to include typefaces that are embellished more than Helvetica - and it's far from cheating when I try the rule. John Dee may have enjoyed this. Rules in $\mathrm{x} \rightarrow \operatorname{prt}(\mathrm{x})$ neatly parse his hieroglyphic monad with its multivalent significance - h's are charged with meaning, too.) Petty scruples block the way. Don't be squeamish - copying and plagiarism are OK in art and design. T. S. Eliot (above) knows poets "borrow" from poets, and that the risk is worthwhile when "the good poet welds his theft into a whole of feeling which is unique, utterly different from that from which it was torn." Duchamp recommends copying in The Blind Man. R. Mutt's Fountain is "plagiarism, a plain piece of plumbing." His theft is trivial and "unique, utterly different" -
Whether Mr. Mutt with his own hands made the fountain or not has no importance. He CHOSE it. He took an ordinary article of life, placed it so that its useful significance disappeared under the new title and point of view - created a new thought for that object.

The idea is to let embedding work for you - to see things in new ways, and to have the means to do something about this without having to invent them, as well. That's what schemas and rules are meant for - to reconfigure what you see as you go on - and trying them is creative. In logic, linguistics, and computer science, creativity is just recursion and identity. (Chomsky is famous for applying this equivalence to language.) This is a pretty good definition - in fact, the best I've found. It's probably a little technical, but at least I know what it means - it's not framed in the usual way in elusive terms that beg for more explanation. And it's easy to locate the source of originality and novelty. But I also think this definition is hopelessly incomplete, at least visually. Without embedding, it doesn't go very far. New things get more and more complex, adding the same old building blocks (units) to the same old building blocks, etc. It's counting higher and higher, with no chance to see what's going on and how this alters in surprising ways. Creativity takes recursion and embedding. Embedding lets me copy without copying by rote - there are no building blocks - in a kind of visual 
improvisation that's full of surprises. Anything can change anytime. This helps to explain why art is art. And it may explain where art comes from, too. Origins are apt to be confused and obscure, yet embedding and shapes cut through the mist with a blunt irony. The origin of art is clear only because seeing is vague and ambiguous. There's art anytime I observe the miscellaneous things around me and change them to see as I please. For example, if figures, formulas, schemas, and rules happen to look like section headings - and why not - then

\section{What next?}

My answer to this question is pretty much the same as my answer to Q1 - anything you want. I've already talked a lot about schemas and rules, and there's a lot more to say about them - about how they're used and what they do when I calculate with shapes. In every direction I look, there are new and useful things to explore. Nonetheless, the question has an established provenance that decides the way to go. This locus adds more about art and design, and how they fit together with calculating.

The question is Alberti's motto - QVID TUM? Lionel March shows that its seven letters have a coded numerical meaning - the entire expression yields the perfect number 28 , that's the sum of its proper divisors. Alberti put art and mathematics together in a single stroke nearly six centuries ago. And shape grammars try this today in another way, when they meld recursion and embedding to calculate by seeing. Alberti does a lot with painting, sculpture, and architecture, and their mathematics. There's recursion - in $O n$ the Art of Building in Ten Books in which cities, buildings, and rooms are compared in a neat passage on compartition - and symmetry, proportion, and perspective. All of this is the stuff of shape grammars. Recursion animates rules. And rules in schemas, for example, $\mathrm{x} \rightarrow \mathrm{x}+\mathrm{t}(\mathrm{x})$ and its several variants in my lattice of schemas for transformation rules, handle symmetry, proportion, and perspective. This may be noteworthy - it's all very easy - but it's not too surprising. Ho hum, you can calculate in shape grammars with some familiar mathematics. That's exactly what shape grammars are for. But then Alberti anticipates the twin tables at the beginning of this essay for basic elements in shapes, and their dimensions and boundaries, and this coincidence may tie to shape grammars in a deeper and more exciting way.

Alberti starts Elements of Painting with basic elements - points, lines, planes, and solids, or bodies, as he calls them - according to Euclid's Elements (cf. my first table):

1. The point is said to be that which cannot be divided at all into any parts.

2. A line is said to be [like] a point stretched out in length. Thus the longitude [length] of a line can be divided, [but] not its latitude [width].

3. A surface is said to be produced almost as though extending the line width-wise, and thus its length [and width] can be divided, [but] not its depth.

4. A body is said to be whatever can be divided by length, by width, and also by depth.

Alberti then goes on to add an original description of basic elements and their boundaries - the similarity to shapes is uncanny (cf. my second table): 
1. We call a body that which is covered by surfaces, on which our vision comes to rest.

2. We call surface that extreme skin of the body, which is encircled by its edge.

3. We call edge the whole circuit, almost [like] borders, where the suface ends, which place I call discrimen, a term taken from the Latins.

4. A discrimen proper is the line drawn from the forehead that divides the hair so that some falls to one side of it and some to the other. Thus using this simile, in our case discrimen will be that length in the middle of two surfaces that divides one from the other, and this length terminates in two points.

5. I call point that extremity where several lengths and discrimens share a common termination.

And Alberti may know that basic elements of dimension greater than zero can be divided anywhere and that they don't exceed finite bounds. Aristotle frames the same idea for continuous magnitudes:

A continuous magnitude can be divided beyond any given smallness, but it cannot be increased above any given greatness.

All of this taken together seems enticingly close to embedding for basic elements, and shapes and their boundaries. Does Alberti, adding to Euclid and Aristotle, have seeing in mind? I'd like to think so - Alberti is pretty good company - but it's a real stretch. There's nothing to suggest calculating with shapes, or that parts of shapes can be cut out and traced in alternative ways. The text I've quoted is more of a pro forma preface to measurement and the mechanics of drawing than anything else. Alberti's art and mathematics seem mostly to delineate geometry and transformations. The Boolean half of shape grammars is incomplete, its outline visible merely here and there. It depends on embedding in my algebras of shapes, and begs for a full explanation and examples of how it works. But I'm prone to wishful thinking - I'm used to seeing whatever I want to and have no qualms about it. Maybe I should try and look again - maybe in a new place. It's easy to be surprised.

The parts of Alberti that impress me most are more directly about art and design, and may appear at first to have little or no mathematical content at all. Alberti's bold account of art and its origin is especially intriguing. It makes embedding unavoidable - it's pure shape grammars with schemas and rules. Alberti sets things up in the beginning few lines of De Statua, sometime around the middle third of the fifteenth century, when he considers how we learn "to create images and likenesses." It's in this marvelous passage:

I believe that the arts of those who attempt to create images and likenesses from bodies produced by Nature, originated in the following way. They probably occasionally observed in a tree-trunk or clod of earth and other similar inanimate objects certain outlines in which, with slight alterations, something very similar to the real faces of Nature was represented. They began, therefore, by diligently observing and studying such things, to try to see whether they could not add, take away or otherwise supply whatever seemed lacking to effect and complete the true likeness. So by correcting and refining the lines and surfaces as the particular object required, they 
achieved their intention and at the same time experience pleasure in doing so. Not surprisingly man's studies in creating likenesses eventually arrived at the stage where, even when they found no assistance of half-formed images in the material to hand, they were still able to make the likeness they wished.

Is this something to take at face value? To be sure, it's easy to find the faces of superstars and deities in strange places - there are many curiosities for sale on eBay. Nonetheless, this is scarcely a start. Alice's Cheshire cat smiles at her from its perch in a tree whenever she blinks. Big dogs and wild things are everywhere you look. And the sky is full of novel creatures on land and sea, day and night. But can I do more with these fanciful images? How are they resolved? How do they change? Are they useful in art and design? Maybe I can do what Alberti suggests with my schemas for rules. It's no big deal to trace a contour or fill in an area "in a tree-trunk or clod of earth" with rules in the inverse of the schema for parts

$$
\mathrm{x} \rightarrow \operatorname{prt}^{-1}(\mathrm{x})
$$

Or I can fill in a contour whether it's complete or not using rules in the schema

$$
\mathrm{x} \rightarrow \mathrm{x}+\mathrm{b}^{-1}\left(\operatorname{prt}^{-1}(\mathrm{x})\right)
$$

This is easy to get adding the identity $\mathrm{x} \rightarrow \mathrm{x}$ to the schema $\mathrm{x} \rightarrow \mathrm{b}^{-1}\left(\operatorname{prt}^{-1}(\mathrm{x})\right)$ that relates point and line to plane, etc. And if the contour merely evokes a fragment of what I'd like to see, then I can try something more ambitious to supply whatever seems lacking to achieve a true likeness

$$
\mathrm{x} \rightarrow \mathrm{x}+\operatorname{prt}^{-1}\left(\mathrm{~b}^{-1}\left(\operatorname{prt}^{-1}(\mathrm{x})\right)\right)
$$

But this schema may be unnecessarily abstruse with too many inverses and nested parentheses. I guess a little calculating is called for, with distinct rules and schemas - then again, my schema equals this one

$$
\operatorname{prt}(\mathrm{b}(\mathrm{x})) \rightarrow \operatorname{prt}(\mathrm{b}(\mathrm{x}))+\operatorname{prt}^{-1}(\mathrm{x})
$$

that may be easier to grasp. In the reverse way, I can outline areas by adding the identity to my schema for random patches in clouds

$$
\mathrm{x} \rightarrow \mathrm{x}+\mathrm{b}\left(\mathrm{t}\left(\operatorname{prt}^{-1}(\mathrm{x})\right)\right)
$$

and letting $\mathrm{t}$ be the identity transformation. And if bits of what I see are wrong, then I can take them away and mark the part that seems right to me now

$$
\mathrm{x} \rightarrow \operatorname{prt}(\mathrm{x})+\mathrm{b}(\operatorname{prt}(\mathrm{x}))
$$

Meaning is mine to make, as I go on in this open-ended process. Whatever rule I try in any schema lets me see more in a new way. And I'm free to look again with the same rule or another one.

(This proves copying is creating. That copying is cheating is an axiom at MIT. But cheating contains creating because $h$ contains $r$. So copying is creating, too. Alberti would likely agree: "slight alterations" go two ways

cheating $\Leftrightarrow$ creating 
I can "add [and] take away ... to effect and complete the true [sic] likeness." Simply try the rule

$$
{ }_{+} \mathrm{h} \rightarrow{ }_{+} \mathrm{r}
$$

in the schema $x \rightarrow \operatorname{prt}(\mathrm{x})$, or the inverse of the rule. An eight-letter word is in an eightletter word, letter for letter. Odd - but not difficult to check by means of embedding, if I type both words with equal spacing and place one over the other, so that cheating conceals creating. How will I ever decide which word to read - the one on top? I guess there really are no non sequiturs.)

Alberti finds various things in tree-trunks and clods of earth, and his extravagant way of seeing (embedding, tracing, copying) extends easily to drawings, paintings, photographs, sculpture, buildings, "ordinary articles of life," etc. They're sources for original art and design, too. And equally, I can go on in myriad ways with the rules in my schemas. I can see as I choose - no-holds-barred. There's embedding everywhere I turn, every time I try a rule. Calculating by seeing makes a real difference. First, embedding gives me a way to go on "by diligently observing and studying," not knowing in advance what I might find. I'm free to change my mind as I calculate with shapes. I'm the one to decide how I see - my experience is mine alone. Then, ready access to schemas and rules lets me interact with shapes continuously with no perceptible break or pause - it's being able to use schemas and rules when I choose, to see what I want and to do what I want, with novel results. The schemas I've got are amiss if I can't use the rules they define as freely as I like. Embedding ensures that my effort isn't wasted. Rules work in just the right way - I only have to look!

I'm endlessly amazed at how straightforward it is to find overt examples of embedding in art and design, and at how often embedding is rediscovered and described anew - even if this is as far as it goes. The various lists I make seem comically haphazard because of everything they miss. I always start a new list with rules - embedding is used whenever a rule is tried. Then several neat examples come reliably into view. Art historians must know that Ernst Gombrich and Michael Baxandall depend on embedding to ground their work, as "projection" - perception à la Rorschach - and "cognitive style." In fact, embedding appears to be intentional across-the-board in art from Alexander Cozens's "blotting" that extends Leonardo da Vinci's use of chance images in design, to Picasso's Bull's Head (bicycle saddle and handlebars) and Baboon and Young Vallauris (toy cars), to Salvador Dali's grandiose "paranoiac-critical method" (the tendency to see things in diverse ways makes paranoia grow - a shape grammar is every paranoid's dream). Donald Schon finds "reframing" and "displacement" in design and like professions - management, planning, psychotherapy, etc. - Ellen Langer roots seeing and other creative experience in "sideways learning" and "mindfulness," and David Perkins implicates "noticing" and "contrary recognition." (Contrary recognition implies that seeing is merely routine - how else can seeing be wrong? Remember what you're trained to see, and mistrust your eyes when you look again. Embedding is too lax identity is enough - and being creative seems hard. Seeing as if for the first time takes a kind of "negative capability." Langer shows this to be vital in learning.) Aptly, William James describes reasoning as "learning and sagacity" - the latter is explicitly embedding and relates both to creativity. Creativity is what teaching should foster and what the studio is for - learning schemas and using the different rules they define with sagacity. Like themes run through art education. In a welcome retreat from "rationality," Elliot Eisner stresses "flexible purposing" (he thanks John Dewey for the term) and visual 
improvisation - redirecting your work and redefining your goals, as options emerge in a stream of surprises. (Lois Hetland and others at Harvard's Project Zero find this in high school art studios. Herbert Simon describes painting and social planning in the same way.) Do surprises comprise a kind of creative consciousness? The list goes on. Ambiguous figures turn up in Neolithic times. The classical Greeks reject checkerboard patterns in weaving because they're visually unstable and so, "barbaric" - that's it for perceptual rivalry. Hieronymus Bosch paints topsy-turvy pictures in which oarsmen in the sky steer boats to clouds at sea. Anatomical drawings - intentional or not - appear in Michelangelo's frescoes in the Sistine Chapel. (Would Alberti or Leonardo or Dali object to this? Art historians today may not be as generous.) Magic viewing stones abound Chinese scholar's rocks, Japanese suiseki, and Korean suseok. And in Mother India, M. F. Husain traces the contours of a naked image in a map of India. (Images and maps may be categorically distinct. This adds a logical twist to the political uproar over Mother India - an image that can change is part of a map that can't. Slick trick! I wonder if the logic police will notice any inconsistency. But this hardly matters: Husain fled Mumbai because of creative excess and a lapse from grace.) These are a few easy examples of seeing - opening your eyes to reconfigure things freely in new ways, and giving up rote norms and prior expectations (aka standards) to make use of what you find. Creative experience isn't routine - it exceeds what memory holds and training requires. Schemas and rules exploit this with embedding in art and design.

Alberti linked mathematics, and art and design - using the one in the other two. The Nexus Network Journal website describes this relationship for architecture:

There are many connections between architecture and mathematics: mathematic principles may be used as a basis for an architectural design, or as a tool for analyzing an existing monument; architecture may be a concrete expression of mathematical ideas, becoming, in a sense, "visual mathematics."

Art and mathematics is putting mathematical results in the hands of artists or designers to make something that's useful or worth looking at, or to describe finished work. Art and design aren't mathematics - they're fine without it, but they use it when it helps to go on, in the same way they use everything else to add something extra. Ideally, art and mathematics enjoy the same kind of relationship that holds for physics and mathematics, although physics may have a stronger and more intimate tie. It's hard to imagine physics without math, and there's a kind of reciprocity - they enrich each other. Nonetheless, mathematics works in art and design. Schemas and rules in shape grammars are useful. Shape grammars do Alberti's mathematics - and then they do more. There's a marvelous twist that makes them inevitable.

Shape grammars turn art and design into mathematics - well, at least calculating - by showing that rules in schemas match what's tried in practice. In fact, you can't avoid using schemas and rules. There's calculating anytime and anywhere you look - tacit and not. That's the gist of my formula

$$
\text { design = calculating }
$$

The trick is to be aware of the equivalence, so that you can use it effectively in teaching and practice. The equivalence goes two ways - there are big gains on both sides of the equal sign. Art and design enlarge calculating with embedding, while calculating with schemas and rules explains how seeing and doing work in art and design. Embedding is 
the key. And ironically, Alberti grasped this, too, finding parts of images and likenesses "in a tree-trunk or clod of earth," and then "correcting and refining the lines and surfaces" to get what he wanted. This is seeing and doing with shapes, and it returns full circle to my original question:

\section{Q1 What rule(s) should I use?}

With schemas and embedding, my answer is never in doubt:

A1 Use any rule(s) you want, whenever you want to.

Schemas ensure that I always have a repertoire of meaningful rules to try, and embedding ensures that whatever rule I use works to surprise me, in an open-ended process. I can always go on to something new. This is calculating by seeing with recursion and embedding. Yes - it's art and design.

\section{Background}

My shape grammars extend Turing machines - shapes, embedding, and continuous transformations allow for more than symbols, identity, and discrete translations. What I see is too fickle to pin down in letters and words. There's no deciding what parts shapes have before rules are tried. Basic elements are continuous - lines, planes, and solids divide freely, so that units fail in art and design. Shape grammars work outside of Turing's logic and combinatorics with their all-or-none bits (0's and 1's). Others also find this way of calculating too limited. John von Neumann would like to calculate with real and complex numbers. Lenore Blum and her collaborators pull this off in numerical analysis and scientific computing. Then Newton's method to solve polynomial equations shows how to calculate, not Turing machines. Turing's bits and codes won't do in processes of this kind. Bits and codes aren't real and complex numbers, the same as symbols aren't shapes. Continuous mathematics (analysis) - like seeing - needs a new way to calculate that isn't combinatory. Science, and art and design are largely two cultures. But when it comes to calculating, there's an amazing convergence. Blum's way of calculating and shape grammars coincide - Turing machines are a special case in both. And there may be more to compare - perhaps calculating over rings, even if this seems to be better suited for numbers than shapes that are more intuitively described in terms of tracing paper, and drawing as a trained draftsman (embedding and maximal elements). Whether any of this is of use technically doesn't matter. It strikes an uncharted arc from science to art and design that proves they're equal, as it bolsters their separate ways of calculating. But shape grammars aren't simply math and rules to calculate. That's far too one-sided and abstract. Shapes are concrete, and rules are inherently phenomenal when they're tried. Shape grammars deal with the vagaries of visual experience in the real world.

H. W. Janson deftly traces chance images (embedding) in Alberti, Leonardo da Vinci, Cozens, and others in "The 'Image Made by Chance' in Renaissance Thought." Kim Williams, Lionel March, and Stephen Wassell provide the English for Alberti's Elementi di Pittura. I read Cecil Grayson's translation of Alberti's De Statua while I was learning about checkerboards and why the classical Greeks shunned them, in Wolfgang Metzger's Gestalt tract, Laws of Seeing. (I like to read unrelated things side by side at the same time, to see if they overlap in any other ways. It's uncanny how seemingly distant viewpoints augment one another.) Mother India highlights the contrast between images and maps in Doxiadis and Papadimitriou's Logicomix - the exact position is on page 211 with grid coordinates A3. A speech bubble points to an image of Christos wandering around, hopelessly lost in Athens: 


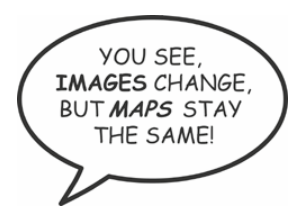

The classical Greeks would have liked Christos's maps - in philosophy (Plato, The Republic, Book VI) and in weaving. But what are maps? How do you get one? What do they cost? Does a map show where to go? Philosophers may know the way - they aren't "blind" like the rest of us, not knowing ahead of time what to see, but have "perfect vision" of the abstract world that's an eternal guide. Maps are "clear patterns" (structures) in the mind's eye or computer memory that can't be seen beside tree-trunks and clods of earth. Otherwise, maps are simply checkerboard patterns (shapes) - grids with precincts in red and black, or any contrasting colors (are these bits?) - that can alter erratically. It's farewell to weaving when nothing stays the same. Are philosophers afraid of this instability? Does it scare artists and designers in the same way? M. F. Husain opts to see rather than settle on what's fixed. Seeing isn't routine when you use your eyes in the concrete world, and aren't obliged to recite by rote the "eternal and unchangeable" things that reason sanctions in philosophy and weaving. Art and design just go on. They're free to "wander in the region of the many and variable" - no end in sight.

A comprehensive discussion of shapes, embedding, and rules and schemas is in my book Shape: Talking about Seeing and Doing. It begins with Plato, and wanders around to calculate in algebras of various kinds. For rules and schemas, the key idea is this: the descriptions given to define a rule in a schema needn't apply to any shape produced from the rule. Descriptions are useful but aren't fixed permanently. What I say I see can change freely as I calculate. For example, the schema

$$
\mathrm{x} \rightarrow \mathrm{x}+\mathrm{t}(\mathrm{x})
$$

defines the rule
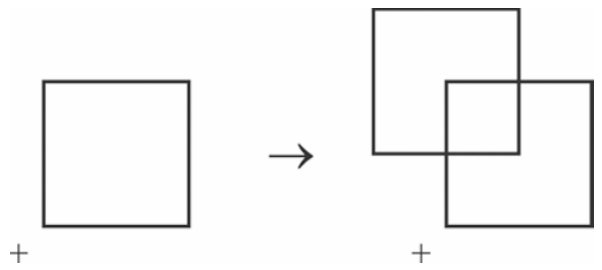

when its right side is two squares of the same size $-\mathrm{x}$ in the left side of the rule, and $\mathrm{x}$ plus $\mathrm{t}(\mathrm{x})$ in the right side. The rule applies to the square

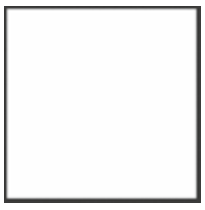

to produce the shape 


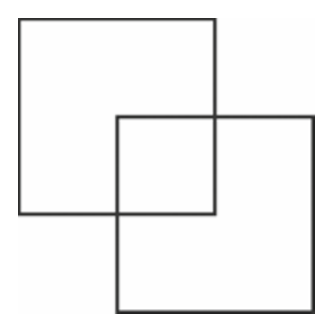

with many surprises. The shape needn't be two squares - maybe it includes a pair of Lshaped, concave hexagons that share two vertices (schemas with nonempty left sides $\mathrm{x}$ define rules for these hexagons and any other parts), or maybe the rule is used again to add a square to the small, central one

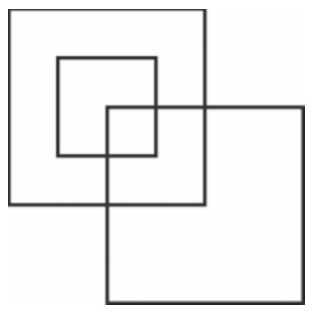

Then the two squares in the shape

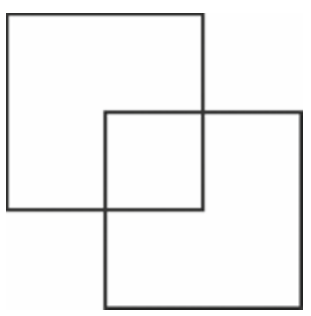

are a square and a concave octagon. There's no reason to keep track of the figures that make up a shape. They disappear without a trace when they combine. Parts alter erratically - I can try any rule I want anywhere I want. And there's more to see adding various transformation rules in the schema

$$
\mathrm{x} \rightarrow \mathrm{t}(\mathrm{x})
$$

Just the rotation rule
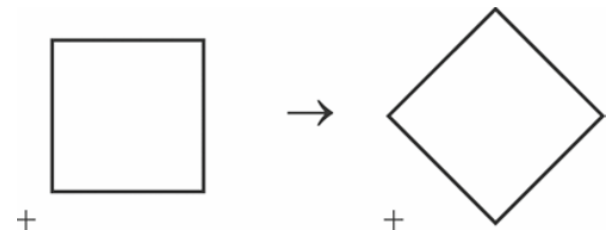

livens things up - there's even some new mathematics with palindromes, when I try (and fail soon enough because there's too much going on all at once) to parse the sides of squares into meaningful pieces of various lengths, that are related in a definite sequence. And translation rules like this one 


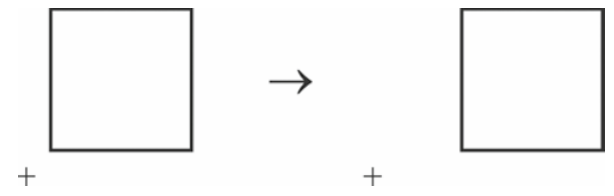

that move squares wherever you want in Cartesian fashion - left or right and then up or down - add to a wonderful variety of nifty changes that are sure to exceed expectations for squares
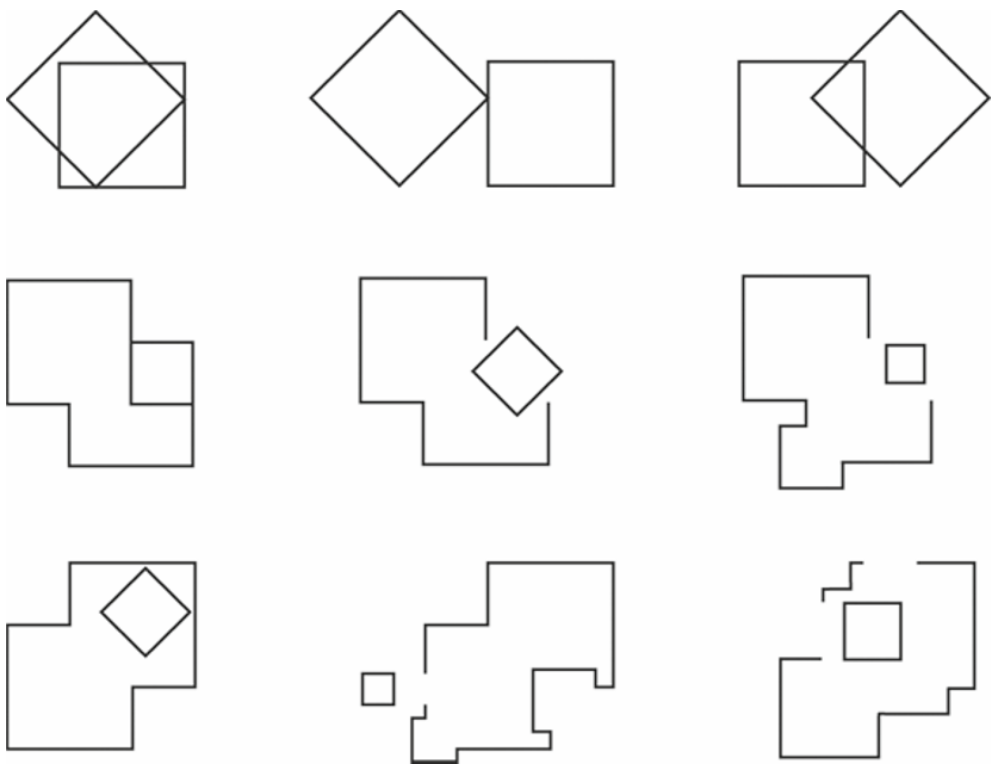

It doesn't take very much rule-wise to make a big difference shape-wise. The leverage can be remarkable. Identities in the schema

$$
\mathrm{x} \rightarrow \mathrm{x}
$$

are enough to show what I mean. But all of this is already in my lattice of schemas for transformation rules. I can follow it through going back and forth between top and bottom, taking various paths. This isn't traversing a classical building from place to place in a rhetorical manner. Nonetheless, my lattice is a pretty good mnemonic that leads to something new. Whoever said art and design aren't calculating? It's no use trying to keep them apart. Calculating goes on and on, doing exactly what I see.

The schemas I've described in this essay are generic. This makes them memorable, and easy to try in novel ways. Schemas are for teaching - there's learning and sagacity. But there are individual stylistic distinctions and other fine points that need to be explained in practice. For example, when individual artists and designers use the division schema $\mathrm{x} \rightarrow \operatorname{div}(\mathrm{x})$, there are distinct results. These differences depend on the assignments given to apply schemas to shapes to calculate. Assignments satisfy predicates when they associate shapes with the variables in schemas. And predicates may restrict how operators are used. The operator $\operatorname{prt}(\mathrm{x})$ and its inverse are pretty general and may be productively reined in with predicates - perhaps $\operatorname{prt}(\mathrm{x})$ picks out polygons or parts that 
are maximally connected. Assignments and predicates involve an added layer of technical description in words and formulas, that's in my book, too. And notice how schemas and assignments recall the ancient distinction for unity and variety - there are many versions, including Alberti's. In my terms, there's unity in a shared repertoire of schemas, and variety in the assignments to try them. Relationships for schemas and assignments, like unity and variety, have yet to be examined in detail, but they're ripe for empirical study and can be tested by calculating. For example, what angles work in ice-rays to limit how divisions are made? Are other angles worth a try? Is there more to ice-rays? This adds a new technique to reinforce known classifications in art and design, and to suggest fresh alternatives.

In one way, schemas and rules go beyond what Alberti recommends. Baxandall notes that Alberti was the first to consider pictures in terms of composizione - a hierarchy of independent parts that's the same for artist and viewer alike, allowing for a kind of communication between them. Alberti took the idea from classical literary criticism where compositio describes the structure of sentences in four tiers. A picture is divided into bodies that are divided into members that are made up of plane surfaces. There's making and seeing going up and down the hierarchy to meet narrative goals. Alberti's use of hierarchy in pictorial composition has been adapted in many ways in art and design J.-N.-L. Durand's system of architectural composition and Alexander's architectural "pattern language" are two instances. But today, the "principle of compositionality" is Frege's in logic - what an expression means depends on the meaning of its parts and how they go together. This informs linguistics and computer science, too, and it's evident in engineering and biology, especially in design education and practice (for example, go to http://biobricks.org for the use of "BioBrick standard DNA parts that encode basic biological functions"). The key idea seems to be inevitable: unit parts with predefined functions combine in compounds with derived functions, and this repeats in a hierarchical ascent, combining compounds and functions to complete a design. Are schemas and rules compositional? The use of operators and inverses, composition, and addition to define schemas has a full-fledged compositional flavor. This may explain some of its allure - it's really neat the way everything fits together in useful schemas. And the rules in schemas are compositional if you choose to use them in this way to calculate with shapes. Even so, rules do far more that's not compositional. Embedding is taking a chance on what to see. There's a new way to go on every time you open your eyes and look again. Parts alter as rules are tried - parts aren't permanent and independent when they combine, but evanescent, fusing and dividing erratically. Putting things together, so that they're fixed in known relationships, may not explain what's there, or even begin to. (This goes for perception and physics alike - the easy congruence between Robert Laughlin's "emergence" and my embedding proves in another way that science, and art and design match. But the equality fails for "reductionism." This provides a compositional alternative to emergence with units and fundamental laws: then embedding is identity à la Turing. Next to reductive science, art and design hold sway. This is good news for art education. Schools can teach art without any qualms - and not because art is instrumental for basic subjects or something to appreciate. The lessons of embedding/emergence unfold when art is art. There are untold questions to ask and answer. For starters, are unit parts emergent or not? Are they fixed once and for all? But physicists aren't worried about art education when there's more science to do. Laughlin is keen to dismiss reports that science is dead with new observations and laws. A reductive theory of everything is a tempting illusion that's hard to deny. Nonetheless, it's folly discovery is open-ended. Embedding/emergence is why in science, and in art and design. 
Laughlin highlights this parallel. Maybe art is physics, and vice versa - they have much in common. "How very interesting.")

Hierarchies feel safe, but they're not - they collapse suddenly as parts change, in one compositional catastrophe after another. It's like having the rug pulled out from under you when you least expect it. Everything is topsy-turvy. It's easy to be afraid or angry you worked hard to figure out what was going on, and to make it all fit just right. Still, the surprise of a fresh start can be exhilarating - you've created (found) something new. The rule

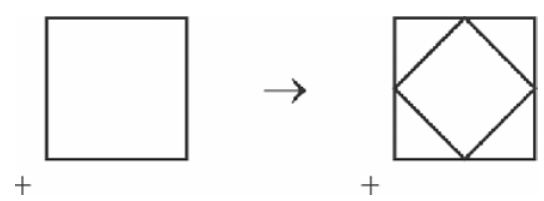

in the schema

$$
\mathrm{x} \rightarrow \mathrm{x}+\mathrm{t}(\mathrm{x})
$$

combines a pair of squares, that the erasing rule

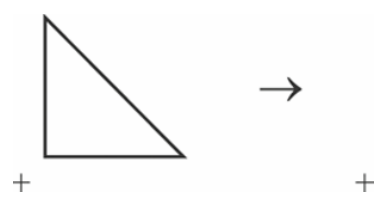

in the schema

$$
x \rightarrow
$$

divides into a quartet of triangles. But how does this work compositionally, if I start with squares? Aren't they fixed once and for all? Where do the triangles come from? And where do the squares go? Is there anything in between squares and triangles that's something to see? Parts don't appear and disappear erratically, without rhyme or reason. What happens to meaning then? It seems simple enough to use one rule or the other in the obvious way to define separate hierarchies for the shape

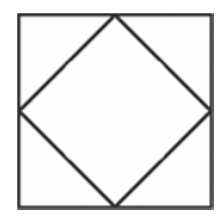

But the hierarchies are evidently incompatible - categorically and numerically distinct because my rules resolve unit parts. What's going on? Do different hierarchies mean different shapes? Let's count their parts by kind to find out. It's perfectly clear: no one believes that two independent squares 


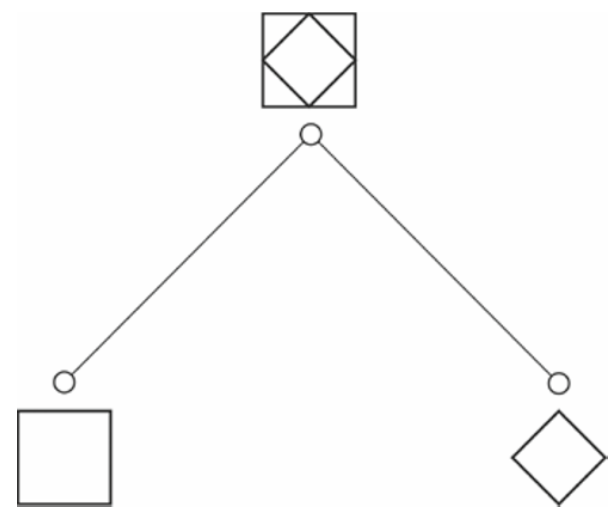

are four independent triangles

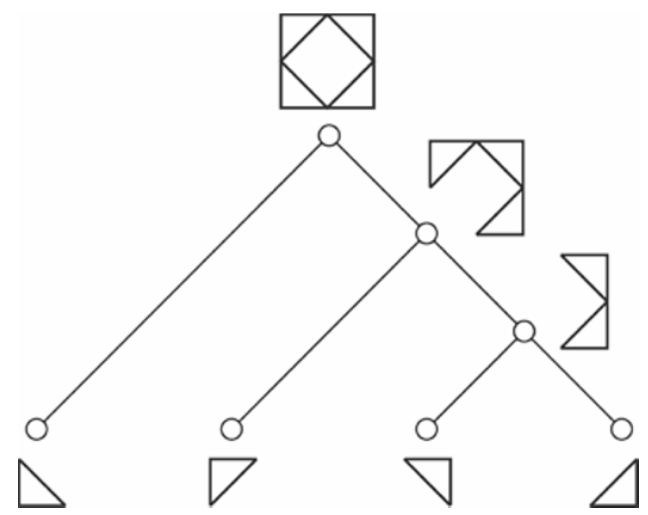

But this is merely counting. I see four triangles when two squares fuse and divide. Can I show how this goes? Perhaps in retrospect - guessing what I'll see before I look won't work: triangles may be pentagons or various other shapes. But once I've seen squares and triangles, I know what to do. First I need to match these figures, in the way they're combined, to define the pieces they have in common - I guess units aren't units after all:

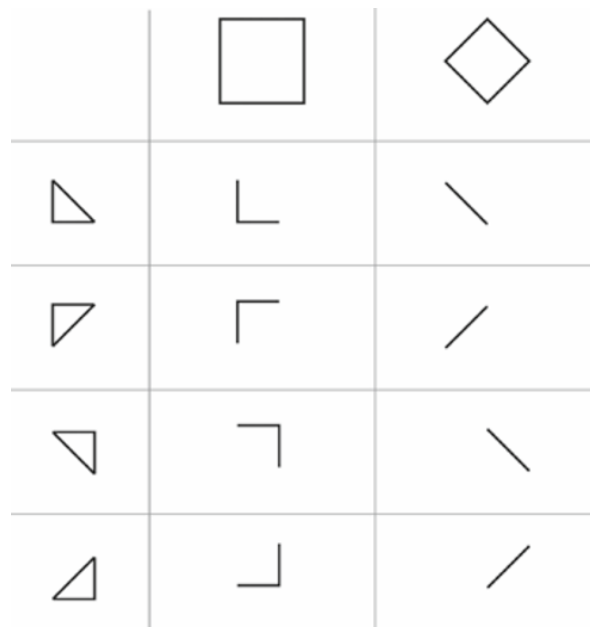


Then I can add these parts of squares and triangles to my original hierarchies to divide shapes in finer detail. The results join across a frontier of common parts in a nonhierarchical network with confusing crossovers:

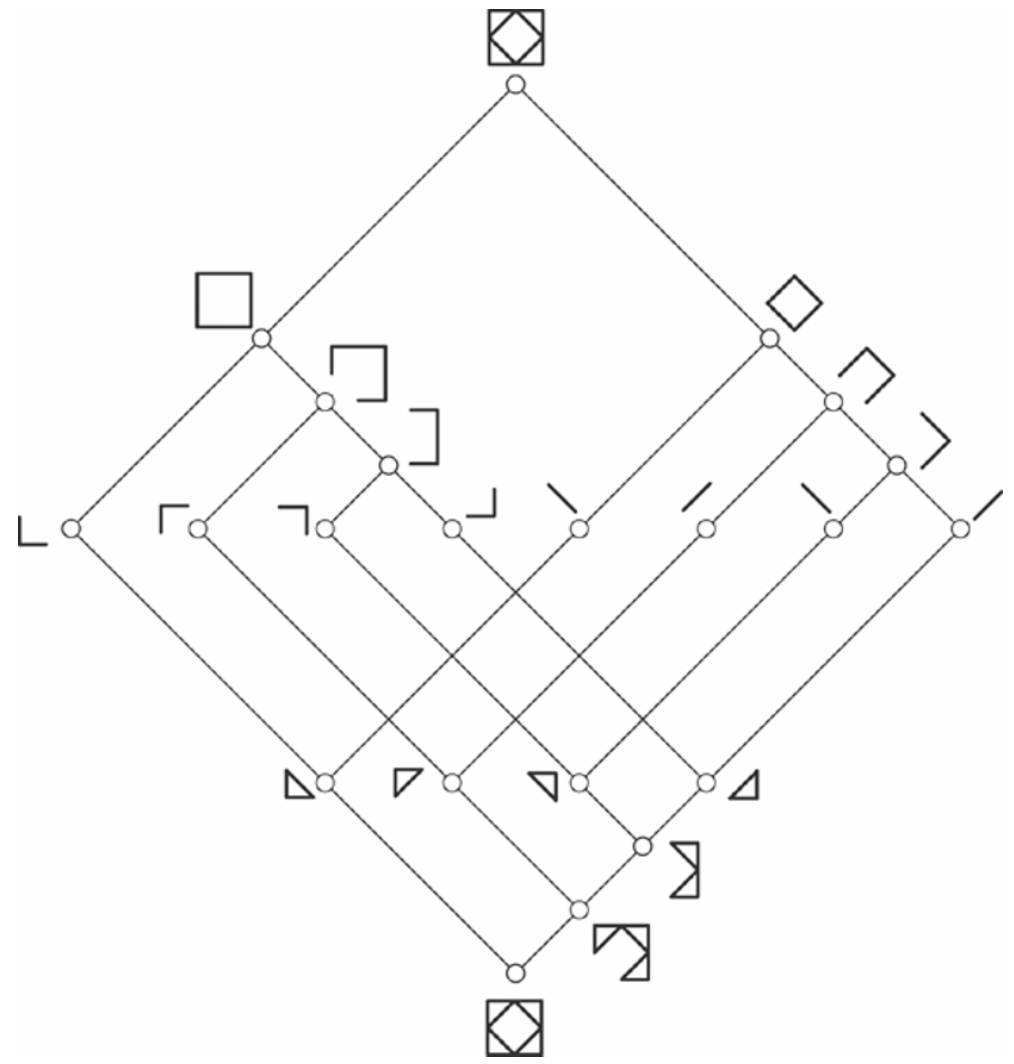

Everything is something else. Going from top to bottom in the network, the four corners of the outside square switch to four separate triangles, while the four sides of the inside square switch in this way, too. In the reverse direction, the right-angled corners of the four triangles make the large square, and the sides of the triangles combine in the small square. Triangles are all alike, with a right angle and a hypotenuse, but neither three sides, as I learned in school, nor three angles, as the word implies - so much for stock definitions. Yet squares divide in this way - they come in two kinds, with four sides or four right-angled corners. Aren't squares all the same - maybe not? How many kinds of squares are there? (Everything is perfectly clear - I embed distinct figures, possibly with alternative structures, or do these figures and structures emerge in a fit of selforganization?)

This isn't compositional: then triangles aren't mixed up in squares. But this is how it goes in art and design, not just once or twice with squares and triangles, but again and again in an open-ended process with whatever it is I happen to see - technically, every time I try a rule. It's worth repeating: parts can change freely anytime with no way of knowing in advance what these changes might be. I have to wait and see. I may divide the shape 


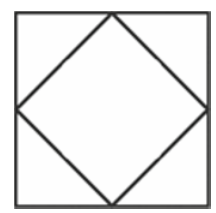

into three kinds of pentagons or congruent hexagons, or some number of big K's and little k's. (Mathematics is never far away. Big K's and little k's fall into a dense series $\kappa$ of dense series, each with a leading $\mathrm{K}$ and successive k's with growing stems. Every series in $\kappa$ is a proper initial segment of every series that follows it, under a similarity transformation that fixes the length of the segment and where little k's are alike.) Where does all of this come from? Alberti's composizione and Frege's principle of compositionality are simply too narrow and inflexible to account for everything there is to see. They play it safe, and miss what's salient next. (I sometimes think that museums also err in exactly the same way, with their "self-guided [sic] audio tours." Words may keep you from using your eyes when an "expert" reminds you of what to see. This fails, especially in education, because embedding is involved.) But composition is too elegant not to give it a serious try - at least it shows you understand what you're doing. Hierarchies are as cognitively seductive as anything I know - it feels good when things fit and mean what you want them to - and hierarchies help to communicate with others. Nonetheless, how do you define a hierarchy before meaningful parts are resolved and fall into place? How many times do you change your mind about what you see, as you wait for something to gel? What makes this possible? Are there reasons to look again? Then, QVID TUM? That's why there are schemas and rules - they're not for composition but to look again. There's nothing to put together, only new things to see. Seeing (perception) precedes understanding and communication. You can't get around it schemas and rules are needed to define hierarchies. They do the trick and a lot more with embedding. There's an alternative principle in this for art and design that's precompositional - the parts you see and use can vary freely and needn't include any of the parts you've combined. There's plenty to do before meaning sticks, and this always starts over when you go on. This is negative capability, indeed.

Composizione has an unruly twin - varietà. In Baxandall's formula, "Composizione disciplines varietà : varietà nourishes composizione." James Gips and I describe this kind of reciprocal relationship for unity (hierarchy) and variety in terms of George Birkhoff's aesthetic measure $\mathrm{M}=\mathrm{O} / \mathrm{C}$ and our own information-theoretic measure $\mathrm{E}_{\mathrm{Z}}$, in our book Algorithmic Aesthetics. My current thoughts on such measures can wait for another time. At the very least, something more dynamic may be necessary. Both Birkhoffs aesthetic measure and $E_{Z}$ fix aesthetic values once and for all, but this needn't be the case for $E_{Z}$. The relationship between schemas and assignments as unity and variety raises many fascinating questions, too. A given repertoire of schemas and various assignments may explain surprising similarities among diverse artists and designers. Baxandall lauds Landino's use of compositione et varietà to compare Filippo and Donatello in precisely this way. This is "one of the prime bearings of Quattrocento cognition." But for schemas and assignments, there's a crucial shift from cognition to perception, and escape from the stringencies of hierarchy to the freedom of embedding. Every time I decide to give up on an idea - this time, unity and variety - it strikes me again in a new way. Maybe ideas are more like shapes than I thought. It's good to keep them around - you never know what you might see next. 
My schemas define rules that produce shapes by calculating. This departs somewhat from the way schemas are ordinarily described and used in art and design, but it may include such schemas, as well. Goethe's Urpflanze is the acknowledged paradigm for schemas and how they're used: it provides a comprehensive survey of plants that are elaborated individually when rules are applied to permute and transform organs of specific kinds. Then Gottfried Semper's Urhutte is an archetype for buildings that's framed in the same way. And perhaps the shape

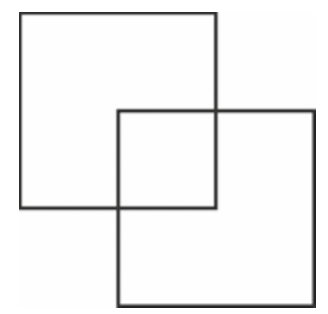

is another example that's easy to vary with transformation rules in the schema $x \rightarrow t(x)$. A few of these variations are shown above. But this may be too general, because the parts of the shape aren't resolved and classified before rules are tried - is it two squares, a square and an octagon, twin hexagons that touch twice, or something else? Labels and like devices are readily available for this purpose whenever they're needed. Shapes and rules may also have the relationship for schema and correction that Gombrich recommends. This is marvelously close to Alberti - schemas are outlines in tree-trunks or clods of earth, and rules are for correcting and refining lines (boundaries) and surfaces (areas) to create various images and likenesses. The relationship between schemas as archetypal shapes, and rules to change them to meet the ongoing demands of experience and circumstance seems to be a very common idea in art and design that works with shapes, and the rules I define in my schemas to calculate.

In architecture, and sometimes in philosophy, a distinction is made between schemas (good) and rules (bad) to contrast a synoptic view of possibilities, and combining building blocks or unit parts in BioBrick, Lego, or Tinkertoy fashion. Semper's Urhutte is an ample summary of buildings, while Durand's system is combinatory with its building "elements" (vocabulary) and rules of composition to put them together (although at times, Durand seems to be a draftsman using embedding). But the distinction may not be that clear. A schema has its combinatory aspects, too - Goethe needs permutations and transformations to vary the organs of his Urpflanze. And a combinatory system with its vocabulary and rules provides a synoptic view of possibilities that unfolds in a recursive process. Maybe schemas and rules are parallel ways of doing the same kinds of things, with the emphasis placed either on similarities in origin and classification (schemas) - for example, this might be the case for a theme and its variations - or on differences in process and elaboration (rules) - as in a language of designs. Using schemas or rules seems to be largely a matter of taste, or perhaps it's just a matter of words that are so intertwined that there's no use trying to untangle subtleties in meaning - it's better to feel your way or to go by sight and sound. And how I use schemas to define rules, and rules (inverses, composition, and addition) to define schemas may imply another equivalence with new interconnections. What about my previous example? Is the shape 


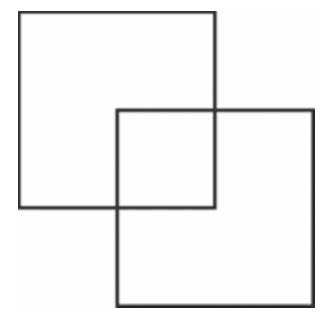

a schema, or is it produced when two squares are combined according to an addition rule in the schema $\mathrm{x} \rightarrow \mathrm{x}+\mathrm{t}(\mathrm{x})$ ? Whatever differences there may be don't amount to much changing a schema and combining shapes lead to the same things. In fact, the schema $\mathrm{x} \rightarrow \mathrm{t}(\mathrm{x})$ is used to define $\mathrm{x} \rightarrow \mathrm{x}+\mathrm{t}(\mathrm{x})$, and is a key part of it. The differences between schemas and rules are trivial, as long as I'm free to describe what I see anyway I want. That's the problem with organs and building elements when they're fixed before rules are tried. And it's the same problem for Goethe and Semper, and Durand - how do their schemas and rules allow for this kind of freedom? Without embedding, neither schemas nor rules let me see as I choose. Limits on what there is to see are set once and for all before I have a chance to look. Seeing is humdrum and routine. This does precious little for architecture, and no more for the rest of art and design. Philosophy may have other aims and goals in mind.

The way I handle schemas in this essay subsumes the schemas in my book, and opens new vistas to explore - especially, in education and practice. Artists and designers are, no doubt, creative. I've been told that this makes them different. (Like views are spread widely. In The Big Noise, Oliver Hardy tells Stan Laurel that inventors are "twisted" and uses a manual gesture to show how. There's little doubt when you see Ollie rotate his hand.) But this is no reason to believe that art and design can't be taught - perhaps differently. There are no limits on creativity using rules defined in schemas, when this involves embedding. (At the end of a lecture not too long ago, I was asked why no one is using shape grammars to teach in the studio. This is one of those silly questions that kids ask - "If you're so smart, why aren't you rich?" - that's supposed to make you stop and think. Well, I didn't have to stop and think, I already knew the answer - no one will let me. That's OK. Moses didn't get to the Promised Land. This may have been God's way of thanking him, by sparing him the embarrassment of not knowing what to do once he got there - seeing the present in the way you remember the past isn't the only way to go on to something new - or the opprobrium of running amok trying to get things done too quickly by fiat and not having the patience, after waiting so long, to give others the chance to learn at their own pace. Maybe ... but it's still more than a little frustrating to know what rules in schemas can do when there's embedding and not to see rules used in practice. It's high time for someone to let someone - I'm not volunteering - try schemas and rules in the studio, not just in an occasional exercise with an apologetic preamble or in elective studios that aren't taken seriously, but everyday throughout the entire curriculum. Half measures, with the option to abandon schemas and rules when they begin to work or because you're afraid they might, simply won't do the job. It may be daring, but there's little to lose. Results in the studio seem to miss the mark - ask students what they learn, and what they think of this. Why not give shape grammars a serious try?) 


\section{Acknowledgments}

Thanks to Lionel March for pointing me to classical texts and commentaries, and for taking the time to discuss Alberti, especially the successive sections I quote from Elements of Painting. To amuse Lionel, I've given 28 additional references - what next? Catherine Stiny did the speech bubble in the "Background" section with "images" in bold, and "maps" in bold and italic. Maps (symbols) are stressed not once but twice probably because it's hard to tell them apart from images (shapes). The confusion is ruinous for maps, but merely another way for images to change - hence the double emphasis and warning. It may be too late. The Greeks couldn't save checkerboard patterns in weaving. Maps look the same, and they're equally at risk, even in today's digital world. That's it for maps - shape grammars forsake stability, routine, and rigorous control to meld seeing and calculating.

\section{References}

AlberTI, Leon Battista. 1972. On Painting and Sculpture. The Latin Texts of De Pictura and De Statua. Cecil Grayson, ed. \& trans. London: Phaidon. 1988. On the Art of Building in Ten Books. J. Rykwert, N. Leach, R. Tavernor, trans. Cambridge, MA: The MIT Press.

- 2010. Elements of Painting. Pp. 142-152 in The Mathematical Works of Leon Battista Alberti. Kim Williams, Lionel March, and Stephen R. Wassell, eds. Basel: Birkhäuser.

AleXander, Christopher. 1979. The Timeless Way of Building. New York: Oxford University Press.

BaXAndall, Michael. 1972. Painting and Experience in Fifteenth-Century Italy. Oxford: Oxford University Press.

BirkHOFF, George D. 1933. Aesthetic Measure. Cambridge, MA: Harvard University Press.

Blum, Lenore, Felipe CuCKer, Michael Shub and Steve Smale. 1998. Complexity and Real Computation. New York: Springer-Verlag. (Perhaps even mathematicians play with ambiguity - at least in book titles.)

Doxiadis, Apostolos and Christos H. Papadimitriou. 2009. Logicomix: An Epic Search for Truth. New York: Bloomsbury.

Durand, Jean-Nicolas-Louis. 2000. Précis of the Lectures on Architecture. David Britt, trans. Los Angeles: The Getty Research Institute.

EISNer, Elliot W. 2002. The Arts and the Creation of Mind. New Haven CT: Yale University Press.

Eliot, T. S. 1948. The Sacred Wood: Essays on Poetry and Criticism. London: Methuen.

Gombrich, E. H. 1960. Art and Illusion: A Study in the Psychology of Pictorial Representation. Princeton: Princeton University Press.

Hetland, Lois, Ellen Winner, Shirley Veenema and Kimberly M. Sheridan. 2007. Studio Thinking: The Real Benefits of Visual Arts Education. New York: Teachers College Press.

JAMES, William. 1981. The Principles of Psychology. Cambridge, MA: Harvard University Press.

Janson, H. W. 1961. The "Image Made by Chance" in Renaissance Thought. Pp. 254-266 in Essays in Honor of Erwin Panofsky. Millard Meiss, ed. New York: New York University Press.

KNight, Terry. Computing with Ambiguity. 2003. Environment and Planning B: Planning and Design 30, 2: 165-180.

Langer, Ellen J. 1997. The Power of Mindful Learning. Reading, MA: Addison-Wesley.

Laughlin, Robert B. 2005. A Different Universe: Reinventing Physics from the Bottom Down. New York: Basic Books.

MARCH, Lionel. 1998. Architectonics of Humanism: Essays on Number in Architecture. New York: Academy Editions.

MetZger, Wolfgang. 2006. Laws of Seeing. Cambridge, MA: The MIT Press.

Oppé, A. P. 1954. Alexander and John Robert Cozens, with a reprint of Alexander Cozens' A New Method of Assisting the Invention in Drawing Original Compositions of Landscape. Cambridge, MA: Harvard University Press. 
Perkins, David N. 1981. The Mind's Best Work. Cambridge, MA: Harvard University Press.

Plato. 1991. The Republic: the Complete and Unabridged Jowett Translation. New York: Vintage Classics.

Roche, Henri-Pierre, Beatrice Wood and Marcel Duchamp, eds. 2007. The Blind Man. lowa City: The University of Iowa Libraries. The International DADA Archive. http://sdrc.lib.uiowa.edu/dada/blindman/index.htm.

SchÖN, Donald A. 1983. The Reflective Practitioner: How Professionals Think in Action. New York: Basic Books.

SIMON, Herbert A. 1981. The Sciences of the Artificial, 2nd ed. Cambridge, MA: The MIT Press.

STINY, George. 2006. Shape: Talking about Seeing and Doing. Cambridge, MA: The MIT Press.

STINY, George and James GIPS. 1978. Algorithmic Aesthetics: Computer Models for Criticism and Design in the Arts. Berkeley and Los Angeles: University of California Press. (Don't bother with the library - download a copy of this book for free, at www.algorithmicaesthetics.org)

von NeumanN, John. 1951. The General and Logical Theory of Automata. Pp. 1-31 in Cerebral Mechanisms in Behavior: the Hixon Symposium. Lloyd A. Jeffress, ed. New York: John Wiley.

\section{About the author}

George Stiny is Professor of Design and Computation at the Massachusetts Institute of Technology in Cambridge, Massachusetts. He joined the Department of Architecture in 1996 after sixteen years on the faculty of the University of California, Los Angeles, and currently heads the $\mathrm{PhD}$ program in Design and Computation at MIT. Educated at MIT and at UCLA, where he received a PhD in Engineering, Stiny has also taught at the University of Sydney, the Royal College of Art (London), and the Open University. His work on shape and shape grammars is widely known for both its theoretical insights linking seeing and calculating, and its striking applications in design practice, education, and scholarship. Stiny has recently completed a book on design and calculating - Shape: Talking about Seeing and Doing (The MIT Press, 2006) and is the author of Pictorial and Formal Aspects of Shape and Shape Grammars (Birkhäuser, 1975), and (with James Gips) of Algorithmic Aesthetics: Computer Models for Criticism and Design in the Arts (University of California Press, 1978). 